\title{
Prevalence of Diabetes and Its Determinants in the Young Adults Indian Population-Call for Yoga Intervention
}

\section{OPEN ACCESS}

Edited by:

Hans Ulrich Häring,

Tübingen University Hospital,

Germany

Reviewed by: Jan Brož,

Charles University, Czechia Peter Mikael Nilsson,

Lund University, Sweden

*Correspondence: Raghuram Nagarathna rnagaratna@gmail.com

Akshay Anand

akshay1anand@rediffmail.com

${ }^{t}$ These authors have contributed equally to this work and share first authorship

Specialty section:

This article was submitted to

Clinical Diabetes,

a section of the journal

Frontiers in Endocrinology

Received: 24 October 2019

Accepted: 07 October 2020

Published: 11 December 2020

Citation:

Nagarathna $R$, Bali $P$, Anand A,

Srivastava V, Patil S, Sharma G, Manasa $K$, Pannu $V$, Singh $A$ and Nagendra HR (2020) Prevalence of Diabetes and Its Determinants in the Young Adults Indian Population-Call for Yoga Intervention.

Front. Endocrinol. 11:507064. doi: 10.3389/fendo.2020.507064

\begin{abstract}
Raghuram Nagarathna ${ }^{1 *}$, Parul Bali ${ }^{2 \dagger}$, Akshay Anand ${ }^{3 *}$, Vinod Srivastava ${ }^{4}$, Suchitra Patil ${ }^{5}$, Guruprasad Sharma ${ }^{5}$, Krishna Manasa ${ }^{5}$, Viraaj Pannu ${ }^{6}$, Amit Singh $^{5}$ and Hongasandra R. Nagendra ${ }^{5}$

1 Vivekananda Yoga Anusandhana Samsthana, Bengaluru, India, ${ }^{2}$ Department of Biophysics, Postgraduate Institute of Medical Education and Research, Chandigarh, India, ${ }^{3}$ Neuroscience Research Lab, Department of Neurology, Postgraduate Institute of Medical Education and Research, Chandigarh, India, ${ }^{4}$ College of Social Work, University of Kentucky, Lexington, KY, United States, ${ }^{5}$ Department of Yoga and Life Science, Swami Vivekananda Yoga Anusandhana Samsthana, Bengaluru, India, ${ }^{6}$ Government Medical College and Hospital Sector 32, Chandigarh, India
\end{abstract}

Background: The young Indian population, which constitutes $65 \%$ of the country, is fast adapting to a new lifestyle, which was not known earlier. They are at a high risk of the increasing burden of diabetes and associated complications. The new evolving lifestyle is not only affecting people's health but also mounting the monetary burden on a developing country such as India.

Aim: We aimed to collect information regarding the prevalence of risk of diabetes in young adults (<35 years) in the 29 most populous states and union territories (7 zones) of India, using a validated questionnaire.

Methods: A user-friendly questionnaire-based survey using a mobile application was conducted on all adults in the 29 most populous states/union territories of India, after obtaining ethical clearance for the study. Here, we report the estimation of the prevalence of the risk of diabetes and self-reported diabetes on 58,821 young individuals below the age of 35 years. Risk for diabetes was assessed using a standardized instrument, the Indian diabetes risk score (IDRS), that has 4 factors (age, family history of diabetes, waist circumference, and physical activity). Spearman's correlation coefficient was used to check the correlations.

Results: The prevalence of high (IDRS score > 60), moderate (IDRS score 30-50), and low (IDRS < 30) diabetes risk in young adults (<35 years) was $10.2 \%, 33.1 \%$, and $56.7 \%$, respectively. Those with high-risk scores were highest (14.4\%) in the Jammu zone and lowest (4.1\%) in the central zone. The prevalence of self-reported diabetes was $1.8 \%$ with a small difference between men (1.7\%) and women (1.9\%), and the highest (8.4\%) in those with a parental history of diabetes. The south zone had the highest $(2.5 \%)$, and the north west zone had the lowest (4.4\%) prevalence. 
Conclusions: Indian youth are at high risk for diabetes, which calls for an urgent action plan through intensive efforts to promote lifestyle behavior modifications during the pandemics of both communicable and noncommunicable diseases.

Keywords: prevalence, diabetes, young adult Indian population, IDRs, lifestyle - related disease

\section{INTRODUCTION}

India is a fast developing economy with a considerable number of diabetes patients. Its health care cost is rising with a deterioration in health standards among the economic productive young population (1-4). It is the country with the second highest numbers after China with 65.1 million diabetes cases that estimated in 2013. This is expected to increase up to 109.0 million in 2035 (5). The highest prevalence of diabetes was noted in low-income countries (LIC) and lowest in high-income countries (HIC) (6). The diabetes primarily affects individuals over 50 years of age in HIC, whereas in middle-income countries (MIC), the prevalence is higher in young individuals, which is the most productive age group. The prevalence in older age again rises as these young individuals age with increased life expectancies $(5,7)$.

Diabetes has become a global pandemic and threat for world health due to demographic variations and cultural differences of societies supplemented by aging phenomena. It is a costly disease that has been identified as the prime causative factor for blindness, lipoprotein abnormalities, or mitochondrial dysfunction causing cardiovascular diseases, renal failure, and amputation in several countries (8-10). The World Health Organization (WHO) has reported 24 million cases of diabetic neuropathy, 5 million cases of retinopathy, and 6 million cases of amputation due to diabetes. The mortality in individuals with diabetes is chiefly due to cardiac complications. Therefore, diabetes can cause undesirable consequences and, hence, needs urgent consideration in the young population in order to timely strategize effective prevention therapies $(8,11)$.

Genetic and environmental factors, such as heredity, change in lifestyle, age, smoking habits, increased alcohol consumption, screen time, parental conflicts, improper sleep, education, and stress, predispose young adults to diabetes, which is exacerbated with diabetic comorbid conditions (12). Obesity is the main risk factor that accounts for $80 \%-85 \%$ of the risks of developing type2 diabetes (13).

The lack of physical activity among the younger population is a matter of concern as $84 \%$ of girls and $78 \%$ of males in Australia did not meet the criteria for minimum physical activity corresponding to their age. As a consequence, females were found to be more overweight than males (14). The risk of diabetes in young adults can be managed by routine physical activity and adopting a healthy and balanced diet, which focuses on the increased intake of dietary fiber (15-17). The WHO strongly recommends reducing the intake of free sugars throughout one's lifetime by avoiding foods or beverages containing added monosaccharides and disaccharides (18). A study was conducted in an urban slum in a large metropolitan city in northern India, which noted a high prevalence of metabolic disorders, such as obesity, dyslipidemia, and diabetes mellitus in middle age, particularly in females in such an economically deprived population (19). Hence, such prevalence studies are required even at a national level to examine the important risk factors in this economic productive young population in order to have effective prevention strategies.

Our study was aimed to estimate the prevalence of low, moderate, and high risk of diabetes in young adults. We conducted a nationwide study by collecting information regarding prevalence of risk of diabetes in young adults using a validated questionnaire. Moreover, the contribution of other sociodemographic factors, such as age, physical activities, yoga, family history, vitals, diet, gender, marriage, education, occupation, and socioeconomic status, were further collected to examine diabetic progression.

\section{METHODS}

\section{Sampling and Study Population}

The study was conducted after ethical clearance from the ethical committee of the Indian yoga association with reference number RES/IEC-IYA/001. The data used in this analysis has been collected during phase 1 of the NMB 2017 trial, a large translational, multicenter, cluster-sampled research trial aimed to assess the efficacy of yoga-based lifestyle modification as a primary prevention strategy for diabetes in a community setting. The methodological details of the study have been reported previously $(20,21)$. In brief, the data collection aimed at screening 4000 adults per district in 60 randomly selected districts representative of the Indian adult population. There were two research associates (who designed the study and monitored work of senior research fellows), 30 senior research fellows (who worked in each district and monitored the work of yoga volunteers for diabetes movement [YVDMS]). The 1200 YVDMs were involved in data collection and yoga training in the next part of the study. These YVDMs were trained for data collection as per their schedule (Supplementary Table 3).

\section{Sample Size Estimation}

Keeping in mind the twin objectives of the study, the sample size estimation was based on the relative risk reduction $(30 \%)$ in prediabetes individuals reported in the Community Lifestyle Improvement Program study (22). We used annual incidence rates of diabetes as $18.3 \%$ in the control conditions as per IDPP-1 study (23). This provided a conversion rate at 3-month follow-up of $4.57 \%$ and $3.0 \%$, respectively, for control and intervention conditions. Using the sample size calculator (http://www.sample-size.net), the required 
sample size for a two-group design with $\alpha=0.05$ and $(1-\alpha)=0.80$ was estimated to be 1949 for each group (a total of 3898 individuals). Factoring an attrition of $20 \%$, the final sample size was estimated to be 4678 individuals with prediabetes. To obtain 4678 individuals with prediabetes, it was calculated that there was a need to screen 77,967 adults above the age of 20 years $(4678 \times 100 / 6$; the least reported prevalence of prediabetes in India has been $6.0 \%$ (24). Thus, the study plan included screening of approximately 155,933 individuals across 60 Indian districts (10\% of all districts as per the 2011 Census of India), assuming a nonresponse rate of $50 \%$. Consequently, the study targeted approximately 4000 adults per district with equal involvement of the urban and rural areas.

\section{Assessments}

We acquired information on diabetes and risk scores by a doorto-door survey using a mobile application with detailed personlevel information about age, gender, income details, educational qualifications, and marital status.

The Indian Diabetes Risk Score (IDRS) developed by Mohan et al. in 2005 was used for risk analysis (25). IDRS is a validated instrument with optimum sensitivity $(72.5 \%)$ and specificity (60.1\%) used widely in India in several studies (26). It is a convenient, simple, and economical tool for the detection of a high-risk population that uses age, waist circumference, parental diabetes history, and physical activity (27) (Supplementary Table 4). The combined scores of the 4 factors contribute to the prediction of risk level of an individual. The individuals with scores $>60,30-50$, and $<30$ are considered to be high, moderate, and low risk, respectively (Supplementary Table 1). We measured waist circumference in centimeters using a measuring tape. Selfreported diabetes was confirmed by checking the medication that they were taking and/or medical reports during the door-to-door visits. The questionnaire was tested for interrater reliability in a preliminary study between two YVDMs using the Kappa coefficient value, which was found to be 0.83 .

\section{Sampling Strategy}

Niyantarit Maduhmeha Bharat (NMB) 2017 was a pan-India randomized multicluster translational trial with dual objectives, namely, a survey for prevalence and lifestyle intervention for the population at high risk and known diabetes (Figure 1). Details of the methods have been published $(20,21)$ earlier. In brief, a fourstage (zone-state-district-urban/rural) strategy was adopted for identifying study locations, using a random cluster sampling method and located households and individuals. Clustering was performed by dividing each state into districts and each district into rural and urban localities. Census enumeration blocks (CEB) were randomly selected from the randomly selected wards, and all eligible individuals (both genders between 20 and 70 years) within the CEB were contacted. The door-to-door survey enlisted eligible individuals and specifically enquired about the status of diabetes and scored them on the IDRS.

Field personnel [1200 volunteers (20/district), supervised by 35 senior research officers and 5 zonal coordinators] were trained in a 5-day residential program to ask appropriate questions in local languages that included practical tests by visiting nearby villages and urban wards.

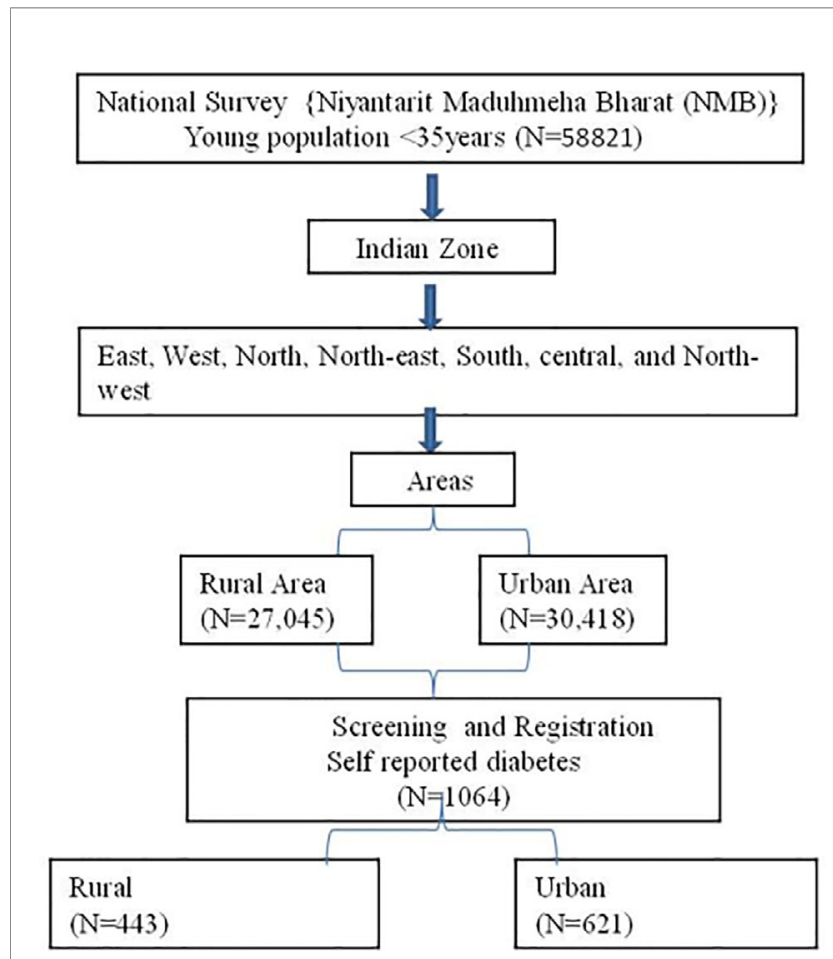

FIGURE 1 | Population sampling strategy of nationwide NMB study.

\section{Statistical Analysis}

Data were analyzed using SPSS (21.0) version. The estimation of prevalence was calculated using the distribution of frequency and percentage using cross tabs descriptive. Chi-square and Fisher exact tests were used for mean differences. Binary logistic regression analysis was done to find the association between independent predictors of diabetes. Self-reported diabetes was considered as a dependent variable. Gender, area, marital status, parental history, IDRS, physical activity, and waist circumference were covariates by keeping the reference factors rural for area, female for gender, vegetarian for diet (Supplementary Table 2) etc. as mentioned in Table 5.

\section{RESULTS}

\section{Prevalence of Self-Reported Diabetes and Its Risks Based on Gender, Marital Status, and Parental History}

According to the national survey (NMB-2017), the young diabetes population was screened across the nation on the basis of IDRS and self-reported diabetes, using validated IDRS; 60,194 individuals were selected on the basis of IDRS score, and 58,821 were selected on the basis of self-reported diabetes as young adults ( $<35$ years). Gender-related risk of diabetes was found to be similar in men and women. The prevalence of selfreported diabetes in young females was $1.9 \%$ and in men $1.7 \%$. On the basis of IDRS risk, no significant difference was found in the female and male diabetes population (Table 1). The marital 
TABLE 1 | Frequency distribution of diabetes participants (self-reported) with context to gender, anthropometric parameters, and different geographical locations in India.

\begin{tabular}{|c|c|c|c|c|c|c|c|c|c|c|c|c|c|}
\hline \multirow[t]{3}{*}{ Variables } & & \multirow[t]{3}{*}{ Total (\%) } & \multicolumn{3}{|c|}{ Diabetes(Self-reported) } & \multicolumn{8}{|c|}{ IDRS } \\
\hline & & & \multirow[b]{2}{*}{$\mathbf{N}$} & \multirow[b]{2}{*}{$\%$} & \multirow[b]{2}{*}{ p-value } & \multirow[t]{2}{*}{ Total } & \multicolumn{2}{|c|}{ Low Risk } & \multicolumn{2}{|c|}{ Moderate Risk } & \multicolumn{2}{|c|}{ High Risk } & \multirow[t]{2}{*}{ p-value } \\
\hline & & & & & & & $\mathbf{N}$ & $\%$ & $\mathbf{N}$ & $\%$ & $\mathbf{N}$ & $\%$ & \\
\hline & & 58821 & 1078 & $1.8 \%$ & & 60194 & 34145 & $56.7 \%$ & 19933 & $33.1 \%$ & 6116 & $10.2 \%$ & $<0.001$ \\
\hline \multirow[t]{2}{*}{ Gender } & Male & 27720 & 479 & $1.7 \%$ & 0.059 & 28287 & 16137 & $57.0 \%$ & 9324 & $33.0 \%$ & 2826 & $10.0 \%$ & 0.157 \\
\hline & Female & 30708 & 585 & $1.9 \%$ & & 31552 & 17836 & $56.5 \%$ & 10473 & $33.2 \%$ & 3243 & $10.3 \%$ & \\
\hline \multirow[t]{2}{*}{ Area } & Rural & 27045 & 486 & $1.8 \%$ & 0.221 & 27998 & 16230 & $58.0 \%$ & 9028 & $32.2 \%$ & 2740 & $9.8 \%$ & $<0.001$ \\
\hline & Urban & 30418 & 574 & $1.9 \%$ & & 30766 & 17029 & $55.4 \%$ & 10502 & $34.1 \%$ & 3235 & $10.5 \%$ & \\
\hline \multirow[t]{3}{*}{ Parental history of DM } & Non- parents & 46521 & 618 & $1.3 \%$ & $<0.001$ & 51009 & 31269 & $61.3 \%$ & 16579 & $32.5 \%$ & 3161 & $6.2 \%$ & $<0.001$ \\
\hline & One parents & 6653 & 333 & $5 \%$ & & 7317 & 2189 & $29.9 \%$ & 2844 & $38.9 \%$ & 2284 & $31.2 \%$ & \\
\hline & Both parents & 1061 & 89 & $8.4 \%$ & & 1136 & 96 & $8.5 \%$ & 381 & $33.5 \%$ & 659 & $58.0 \%$ & \\
\hline \multirow[t]{3}{*}{ Marital status } & Married & 40525 & 805 & $2.0 \%$ & $<0.001$ & 42166 & 22225 & $52.7 \%$ & 15049 & $35.7 \%$ & 4892 & $11.6 \%$ & $<0.001$ \\
\hline & Un-married & 15383 & 236 & $1.5 \%$ & & 16097 & 10686 & $66.4 \%$ & 4320 & $26.8 \%$ & 1091 & $6.8 \%$ & \\
\hline & Separated & 65 & 1 & $1.5 \%$ & & 73 & 42 & $57.5 \%$ & 23 & $31.5 \%$ & 8 & $11.0 \%$ & \\
\hline \multirow[t]{4}{*}{ BMl } & $\begin{array}{l}\text { Under weight } \\
(<18.5)\end{array}$ & 3665 & 41 & $1.1 \%$ & $<0.001$ & 3884 & 3103 & $79.9 \%$ & 677 & $17.4 \%$ & 104 & $2.7 \%$ & $<0.001$ \\
\hline & $\begin{array}{l}\text { Normal weight } \\
(18.5-25)\end{array}$ & 21797 & 293 & $1.3 \%$ & & 23078 & 15061 & $65.3 \%$ & 6463 & $28.0 \%$ & 1554 & $6.7 \%$ & \\
\hline & $\begin{array}{l}\text { Over- weight } \\
(25-30)\end{array}$ & 8548 & 201 & $2.4 \%$ & & 9031 & 3858 & $42.7 \%$ & 3607 & $39.9 \%$ & 1566 & $17.3 \%$ & \\
\hline & $\begin{array}{l}\text { Obese } \\
(>30)\end{array}$ & 3291 & 110 & $3.3 \%$ & & 3448 & 1277 & $37.0 \%$ & 1309 & $38.0 \%$ & 862 & $25.0 \%$ & \\
\hline \multirow[t]{3}{*}{ Waist circumference } & High Risk & 10556 & 338 & $3.2 \%$ & $<0.001$ & 11230 & 566 & $5.0 \%$ & 6887 & $61.3 \%$ & 3777 & $33.6 \%$ & $<0.001$ \\
\hline & Moderate risk & 17025 & 346 & $2 \%$ & & 18706 & 5776 & $30.9 \%$ & 10733 & $57.4 \%$ & 2197 & $11.7 \%$ & \\
\hline & Normal & 26617 & 355 & $1.3 \%$ & & 29526 & 27212 & $92.2 \%$ & 2184 & $7.4 \%$ & 130 & $0.4 \%$ & \\
\hline \multirow[t]{3}{*}{ IDRS } & Low- risk & 30775 & 335 & $1.1 \%$ & $<0.001$ & & & - & & & & & - \\
\hline & Moderate risk & 18442 & 338 & $1.8 \%$ & & & & & & & & & \\
\hline & High- risk & 5638 & 366 & $6.5 \%$ & & & & & & & & & \\
\hline \multirow[t]{4}{*}{ Physical activity } & No & 7274 & 148 & $2.0 \%$ & 0.084 & 12191 & 4828 & $39.6 \%$ & 4087 & $33.5 \%$ & 3276 & $26.9 \%$ & $<0.001$ \\
\hline & Mild & 12249 & 265 & $2.2 \%$ & & 23215 & 8582 & $37.0 \%$ & 12434 & $53.6 \%$ & 2199 & $9.5 \%$ & \\
\hline & Moderate & 21921 & 395 & $1.8 \%$ & & 16581 & 12979 & $78.3 \%$ & 2983 & $18.0 \%$ & 619 & $3.7 \%$ & \\
\hline & Vigorous & 15028 & 246 & $1.6 \%$ & & 8207 & 7756 & $94.5 \%$ & 429 & $5.2 \%$ & 22 & $0.3 \%$ & \\
\hline
\end{tabular}

status analysis revealed that $1.5 \%$ of unmarried, $2.0 \%$ of married, and $1.5 \%$ of separated individuals were found to have selfreported diabetes. Among these, married (11.6\%) and separated $(11.0 \%)$ individuals were under higher risk of diabetes than unmarried ones $(p<0.001)$ (Table 1). Similarly, the frequency distribution of unmarried, married, and separated people based in IDRS was also found to be significantly different among these groups.

Interestingly, it has been found that $1.3 \%, 5 \%$, and $8.4 \%$ of diabetic subjects were self-reported with no parental history of diabetes, one diabetes parent, and both diabetes parents with diabetic history, respectively $(P<0.001)$. Frequency distribution based on the parental history of diabetes has also reflected significantly higher numbers in high IDRS scores as compared to low-risk IDRS. Results suggest the inheritance pattern of diabetic condition, which may be triggered with familial lifestyle or genetic susceptibility of parents and trait transmission in siblings.

\section{Prevalence of Self-Reported Diabetes and Its Risk Based on BMI, Physical Activity, and Waist Circumference}

Participants were categorized into normal, underweight, and overweight/obese. It was found that the overweight $(2.4 \%)$ and obese $(>30)$ (3.3\%) young population was at significantly higher risk of diabetes than the normal (1.3\%) and underweight (1.1\%) young population (Table 1). The percentage of self-reported diabetes individuals with normal, high, and moderate health risks based on waist circumference is as follows: $1.3 \%, 3.2 \%, 2.0 \%$ $(p<0.001)$. The IDRS scores (based on waist circumference) were also significantly higher in high-risk participants based on waist circumference of individuals, i.e., almost $33.6 \%$ more than moderate (11.7\%) and normal (0.4\%) individuals (Table 1).

The frequency distribution based on physical activities was also in concordance with the BMI and waist circumference of the participants. It was found that the proportion of individuals who performed no, mild, moderate, or vigorous physical exercise were comparable.

\section{Differential Frequency of Self-Reported Diabetes and Its Risk Factors Based on Different Indian Geographical Location}

The zone-wise prevalence of diabetes (self-reported) was significantly different $(<0.001)$ and reported as follows in descending order: south, north, east, northeast, central, west, and Jammu. However, no gender-wise significant differences were found (Table 2). Zone-wise distribution of high and moderate IDRS risk of diabetes was also reported as south, north, west, Jammu, northeast, east, and central (Table 3), and the data showed significant differences among these groups. 
TABLE 2 | Zone-wise frequency distribution of self-reported diabetes participants.

\begin{tabular}{|c|c|c|c|c|c|c|c|c|}
\hline \multirow[t]{2}{*}{ Zone } & \multirow[t]{2}{*}{ Total (N) } & \multirow[t]{2}{*}{ Diabetes (\%) } & \multirow[t]{2}{*}{ p-value } & \multirow[t]{2}{*}{ Gender } & \multirow[t]{2}{*}{ Total (N) } & \multicolumn{2}{|c|}{ Diabetes } & \multirow[t]{2}{*}{ p-value } \\
\hline & & & & & & $\mathbf{n}$ & $\%$ & \\
\hline \multirow[t]{2}{*}{ North } & 6565 & 117 (1.8\%) & $<0.001$ & Male & 2857 & 45 & $1.6 \%$ & $=0.242$ \\
\hline & & & & Female & 3615 & 71 & $2.0 \%$ & \\
\hline \multirow[t]{2}{*}{ South } & 15734 & 389 (2.5\%) & & Male & 7465 & 182 & $2.4 \%$ & $=0.971$ \\
\hline & & & & Female & 8050 & 197 & $2.4 \%$ & \\
\hline \multirow[t]{2}{*}{ East } & 8611 & 152 (1.8\%) & & Male & 3901 & 60 & $1.5 \%$ & $=0.168$ \\
\hline & & & & Female & 4663 & 90 & $1.9 \%$ & \\
\hline \multirow[t]{2}{*}{ West } & 8812 & 135 (1.5\%) & & Male & 4564 & 64 & $1.4 \%$ & $=0.296$ \\
\hline & & & & Female & 4235 & 71 & $1.7 \%$ & \\
\hline \multirow[t]{2}{*}{ Central } & 8889 & $151(1.7 \%)$ & & Male & 4148 & 67 & $1.6 \%$ & $=0.555$ \\
\hline & & & & Female & 4725 & 84 & $1.8 \%$ & \\
\hline \multirow[t]{2}{*}{ North-West } & 4857 & 44 (0.9\%) & & Male & 2095 & 15 & $0.7 \%$ & $=0.224$ \\
\hline & & & & Female & 2762 & 29 & $1.0 \%$ & \\
\hline \multirow[t]{2}{*}{ North-East } & 5353 & 90 (1.7\%) & & Male & 2690 & 46 & $1.7 \%$ & $=0.792$ \\
\hline & & & & Female & 2658 & 43 & $1.6 \%$ & \\
\hline
\end{tabular}

TABLE 3 | Zone-wise risk of diabetes based on IDRS score.

\begin{tabular}{|c|c|c|c|c|c|c|c|c|c|}
\hline & & \multicolumn{7}{|c|}{ Zone } & \multirow[t]{2}{*}{ p-value } \\
\hline & & $\begin{array}{c}\text { North } \\
(n=6844)\end{array}$ & $\begin{array}{c}\text { South } \\
(n=12317)\end{array}$ & $\begin{array}{c}\text { East } \\
(\mathrm{n}=9650)\end{array}$ & $\begin{array}{c}\text { West } \\
(n=9507)\end{array}$ & $\begin{array}{c}\text { Central } \\
(n=10294)\end{array}$ & $\begin{array}{c}\text { Jammu } \\
(n=5370)\end{array}$ & $\begin{array}{l}\text { North East } \\
(\mathrm{n}=6212)\end{array}$ & \\
\hline \multirow[t]{3}{*}{ IDRS } & High risk & 848 (12.4\%) & 1699 (13.8\%) & 727 (7.5\%) & 1126 (11.8\%) & 425 (4.1\%) & 774 (14.4\%) & 517 (8.3\%) & $<0.001$ \\
\hline & Moderate risk & 2312 (33.8\%) & 5978 (48.5\%) & 2919 (30.2\%) & 3174 (33.4\%) & 1607 (15.6\%) & 2114 (39.4\%) & 1829 (29.4\%) & \\
\hline & Low risk & 3684 (53.8\%) & 4640 (37.7\%) & $6004(62.2 \%)$ & 5207 (54.8\%) & 8262 (80.3\%) & 2482 (46.2\%) & 3866 (62.2\%) & \\
\hline
\end{tabular}

The proportion of high, moderate, and low risks based on IDRS was calculated zone-wise that includes north, south, east, west, central, Jammu, and north-east India.

However, frequency distribution of self-reported diabetes was comparable in urban areas $(1.9 \%)$ and rural localities $(1.8 \%)$ that showed statistically insignificant differences between the two $(p=$ 0.221 , Table 1). The proportion of individuals taking treatment to control diabetes was estimated. Results demonstrated that only $54.5 \%$ of the young diabetes adults were taking treatment to control diabetes, and there were no medications being taken by $45.5 \%$ of the diabetes subjects (Table 4 ).

\section{Relative Risk of Diabetes}

By using logistic regression, high- and moderate-risk young adults (based on IDRS) were found to have higher odds of developing diabetes as compared to low-risk young adults. Unmarried young adults had 1.290 higher odds $(p<0.001)$ of diabetes as compared to married individuals. The comparison was made for relative risk of diabetes (28) within each parameter using a binary multinomial logistic regression analysis. Both higher and lower odds of diabetes as compared to the reference variable have been reproduced in Table 5. Logistic regression analysis to see the impact of BMI and food habits on IDRS scoring has revealed the imperative impact of both on diabetes.

TABLE 4 | Proportion of self-reported diabetes individual prescribed for treatment.

\begin{tabular}{lcc}
\hline & Treatment & No treatment \\
\hline Diabetes Subjects & $54.5 \%$ & $45.5 \%$
\end{tabular}

Obese participants can significantly stimulate the diabetic condition (Table 6).

\section{DISCUSSION}

India is the second-largest populated country in the world. It is estimated that India has more of a young population compared to other countries in the world. According to the 2011 census, out of the total population, about $65 \%$ of the population of India are under the age of 35 (29). India has more than 40 million diabetes cases with a good majority across the nation not aware of the disease and comorbid factors. As diabetes risk varies with increasing age, early detection and intervention may prevent serious health complications and healthcare-related cost. The diabetes population in young adults has a tendency to become readily or more vulnerable to comorbid diabetes illnesses (30). Complications related to diabetes are becoming a major cause of morbidity and mortality in the young population (31). Rapidly increasing burden of Diabetes in the young might reder population to early predisposition to age related disorders which have no treatment (32-35). Primarily, the risk of diabetes is associated with age, obesity, parental diabetes history, smoking, type of diet, and physical inactivity (36).

The studies have shown that diabetes might be linked to genetic and environmental factors (37). Parental history is generally believed to play a major role in the prediction of 
TABLE 5 | Multinomial logistic regression analysis showing the odds of diabetes within each variable.

\begin{tabular}{|c|c|c|c|c|}
\hline Variable & Reference Variable & $\begin{array}{l}\text { Dependent variable with } \\
\text { self reported diabetes }\end{array}$ & Odds Ratio (95\% Cl) & p-value \\
\hline Area & Rural & Urban & 1.364(1.206-1.542) & 0.000 \\
\hline Gender & Male & Female & $1.197(1.061-1.351)$ & 0.003 \\
\hline \multirow[t]{2}{*}{ Parental DM history } & Both non Diabetes & One parent diabetic & 3.893(3.399-4.459) & $<0.001$ \\
\hline & & Two parent diabetic & 6.633(5.266-8.355) & $<0.001$ \\
\hline Marital status & Unmarried & Married & $1.290(1.116-1.491)$ & 0.000 \\
\hline Diet & Vegetarian & Non-vegetarian & $2.208(0.757-5.488)$ & 0.159 \\
\hline Yoga practice & No & Yes & $1.613(1.332-1.954)$ & $<0.001$ \\
\hline \multirow[t]{2}{*}{ IDRS } & Low risk & High risk & $6.211(5.340-7.223)$ & $<0.001$ \\
\hline & & Moderate risk & $1.674(1.438-1.950)$ & $<0.001$ \\
\hline \multirow[t]{3}{*}{ Physical activity } & Vigorous & Moderate & $0.801(0.852-0.984)$ & 0.035 \\
\hline & & Mild & 0.894(0.738-1.088) & 0.203 \\
\hline & & No & $1.065(0.869-1.305)$ & 0.548 \\
\hline \multirow[t]{2}{*}{ Waist circumference } & Normal risk & Moderate risk & $1.535(1.322-1.782)$ & $<0.001$ \\
\hline & & High risk & $2.447(2.105-2.845)$ & $<0.001$ \\
\hline \multirow[t]{2}{*}{$\mathrm{BMI}$} & Underweight & Overweight & $2.128(1.518-2.985)$ & 0.000 \\
\hline & & Obese & $3.057(2.129-4.389)$ & 0.000 \\
\hline
\end{tabular}

The odds ratio was calculated for geographical location, gender, marital status, parental DM history, diet, yoga practice, IDRS, physical activity, waist circumference, and BMI.

TABLE 6 | Logistic regression to see the association of BMI and food habit with IDRS scores.

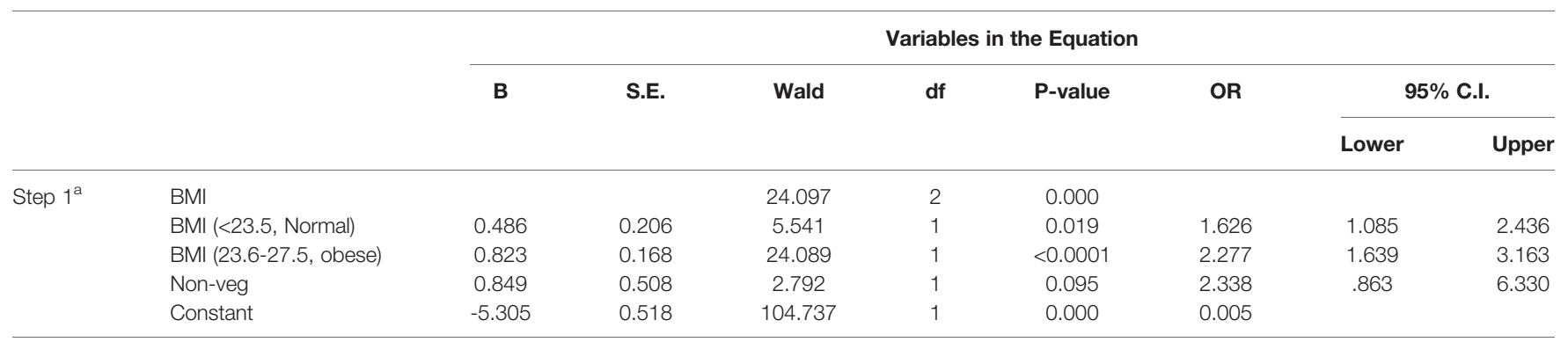

diabetes. Therefore, we analyzed the percentage prevalence of self-reported diabetes in both parents with diabetes, no parents with diabetes, and one parent diabetes. This survey revealed that, overall, $1.3 \%$ of the diabetes cases had no parental history, which is possibly explained by the change in lifestyle or some epigenetic factors that can contribute to the development of such diabetes cases. Our study demonstrates that young adults with both diabetes and one diabetes parent are at a high risk of developing diabetes as compared to both nondiabetes parents. Comparison of the relative risk of diabetes within each variable showed significant results except gender. We observe that marital status (separated vs. married) was also found to be associated with diabetes risk. The current study suggests that unmarried individuals are also at increased risk of diabetes but less than married and separated people. This could be possibly because of more stress or hormonal changes in unmarried as compared to married people, which may be the contributing factors for developing diabetes risk; however, further studies are required to conclude these possibilities. Although, it is difficult to speculate why unmarried individuals as compared to separate and married were more affected by diabetes, it is possible that the former group ignored health and wellness as compared to the latter.

It was also found that the risk of diabetes varies according to areas and zones. Based on the IDRS score, the study found that the urban young population is under higher risk of diabetes than the rural counterparts. The southern region was found to have more young diabetes population i.e., $2.5 \%$. The study conducted in India shows a similar prevalence of diabetes in the urban population (24). Nevertheless, the distribution characters in all cities were found to be comparable except socioeconomic status.

Dietary habits played a vital role in enhancing the diabetes risk and awareness, and more attention is required regarding this aspect. Diet, with high glycemic load, results in diabetes complications (38). Interestingly, the study outcomes reveal that the young vegetarian population was under a higher risk of diabetes than the nonvegetarian self-reported diabetes population. This reflects the predominant consumption of vegetarian diets rich in carbohydrates, such as rice, wheat, oil, and fatty foods. Additionally, it is worth noting that consumption of sweets is also an integral part and parcel of the Indian culture, which could be responsible for the development of diabetes among the young adult population (39). However, other studies suggest that the typical vegetarian diet helps in reducing the diabetes risk (40). This controversial fact needs further investigation, including the amount and types of diet with an appropriate control group. India is the habitat of different religions and many cultures having different eating behaviors and unique lifestyles. Hence, these variations, cultural diversity, customs, and heterogeneity across the nation are great challenges 
to associate it with diabetes even though it has been shown that changes in the dietary pattern may reduce the chance of diabetes (41).

The individuals who showed high IDRS but did not develop diabetes need to be followed up for any late development of diabetes, especially if it had not manifested in early life $(<35$ years). There is a need to develop a cost-effective and preventive management program to reduce or prevent diabetes complications in young adults. As yoga is emerging as a costeffective lifestyle intervention and alternative, its efficacy in the prevention of diabetes can be examined in Indian population studies where its acceptability is high. The level of physical activity index among young adults with diabetes shows that $26.9 \%$ of the young adults with high-risk diabetes did not perform any physical activity, and $9.5 \%$ and $3.7 \%$ of these individuals were engaged in mild and moderate physical activity, respectively, indicating that a sedentary lifestyle is one of the major risk factors in the development of diabetes among younger adults. Results demonstrated that only $54.5 \%$ of the young diabetes adults were taking treatment to control diabetes, and there were no medications being taken by $45.5 \%$ of the diabetes subjects (Table 4). The possible reason can be that patients might be asymptomatic as we analyzed in young population.

Studies show that yoga helps in the activation of the hypothalamic pituitary axis and sympatho-adrenal component known to inhibit glucose uptake by inhibiting insulin release, inducing insulin resistance and increasing hepatic glucose production (42). Vigorous exercises have shown to increase HDL level, and moderate intensity exercises are effective in reducing VLDL (43). Young adults with higher risk for diabetes may benefit from practicing yoga as well as managing their obesity by engaging in vigorous and moderate intensity exercises to manage their lipid profile (Figure 2).

Interestingly, young diabetes patients are amenable to reversal by intensive lifestyle intervention as seen in this young diabetes study (44). The diabetes young population has greater chances of reversal because of reduced risk factors as compared to the aged group. Diabetes, if it remains untreated/undetected in the early stage of life, may become more complicated in the later stage of life (30). Young diabetes often remains undetected as aged people continue to be tested for multiple health problems and identification and corresponding intervention programs are essential for this population. This study suggests that about one fourth of the young adult population in India is at a high risk of developing diabetes and in need of the public provision of lifestyle modification programs.

\section{Limitations}

The study used cluster sampling, which might have contributed to the sample selection bias. As a result, some subjects with diabetes might have refused to admit to having diabetes. It is also possible that a few subjects are wrongly believed to have diabetes, and there is no validation of such self-reported diabetes. Furthermore, undiagnosed diabetes could be another confounder. Subjects frequently ignore the subtle signs and symptoms of asymptomatic diabetes. The possibility of underestimation of the prevalence of diabetes in the proposed population may be the main limitation.

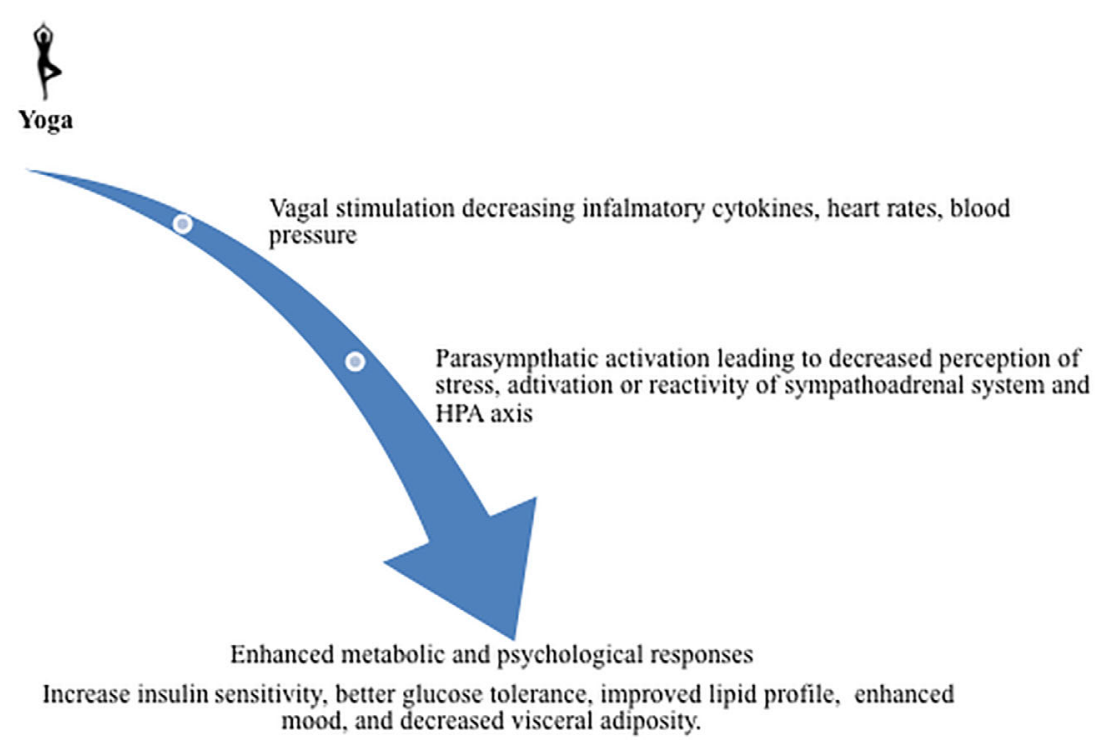

FIGURE 2 | Yoga benefit in decreasing diabetic risks: The studies show that yoga causes vagal stimulation and, therefore, decreases inflammatory cytokines and heart rate as well as blood pressure. The yoga activates parasympthatic system that possibly leads to decreased perception of stress, activation, or reactivity of the sympathoadrenal system and HPA axis. Further, it may enhance metabolic and psychological responses, insulin sensitivity, glucose tolerance, improved lipid profile, mood, and decreased visceral adiposity. 


\section{DATA AVAILABILITY STATEMENT}

All datasets generated for this study are included in the article/ Supplementary Material. Data is available with the principal investigator.

\section{ETHICS STATEMENT}

Ethical permission obtained from Institutional Ethics Committee (IEC) meeting held at Indian Yoga Association, Morarji Desai National Institute of Yoga with reference no. RES/IEC-IYA/001 dated 16th Dec 2016.

\section{AUTHOR CONTRIBUTIONS}

$\mathrm{RN}$ is a grant PI involved in conceptualization, editing of manuscript. $\mathrm{PB}$ was involved in original writing and data analysis. VS edited the manuscript. AA was involved in conceptualization of manuscript. VS edited the manuscript. SP was involved in data curation and analysis. GS and AS were involved in the acquisition of data. VP was involved in writing, editing and collection of data on site as physician. HRN was

\section{REFERENCES}

1. Owen N, Sparling PB, Healy GN, Dunstan DW, Matthews CE. Sedentary behavior: emerging evidence for a new health risk, Mayo Clinic Proceedings. United States: Elsevier on behalf of the Mayo Clinic (2010). p. 1138-41.

2. Akari S, Mateti UV, Kunduru BR. Health-care cost of diabetes in South India: A cost of illness study. J Res Pharm Pract (2013) 2:114.

3. Barik D, Arokiasamy P. Rising health expenditure due to non-communicable diseases in India: an outlook. Front Public Health (2016) 4:268.

4. Mather H, Verma N, Mehta S, Madhu S, Keen H. The prevalence of known diabetes in Indians in New Delhi and London. I Med Assoc Thailand Chotmaihet Thangphaet (1987) 70:54-8.

5. Guariguata L, Whiting DR, Hambleton I, Beagley J, Linnenkamp U, Shaw J, et al. Global estimates of diabetes prevalence for 2013 and projections for 2035. Diabetes Res Clin Pract (2014) 103:137-49.

6. Dagenais GR, Gerstein HC, Zhang X, McQueen M, Lear S, Lopez-Jaramillo P, et al. Variations in diabetes prevalence in low-, middle-, and high-income countries: results from the prospective urban and rural epidemiological study. Diabetes Care (2016) 39:780-7.

7. Scully T. Diabetes in Numbers. Nature (2012) 485:S2-3.

8. Tol A, Sharifirad G, Shojaezadeh D, Tavasoli E, Azadbakht L. Socio-economic factors and diabetes consequences among patients with type 2 diabetes. JEduc Health Promotion (2013) 2.

9. Krentz AJ. Lipoprotein abnormalities and their consequences for patients with type 2 diabetes. Diabetes Obes Metab (2003) 5:S19-27.

10. Schrauwen-Hinderling VB, Kooi ME, Schrauwen P. Mitochondrial function and diabetes: consequences for skeletal and cardiac muscle metabolism. Antioxid Redox Signaling (2016) 24:39-51.

11. Connolly V, Roper N, Unwin N, Jones S, Bilous R, Kelly W. Quality of diabetes care, material deprivation and mortality: P80. Diabetic Med Supplement (2002) 19.

12. Murea M, Ma L, Freedman BI. Genetic and environmental factors associated with type 2 diabetes and diabetic vascular complications. Rev Diabetic Stud: RDS (2012) 9:6.

13. Carr MC, Brunzell JD. Abdominal obesity and dyslipidemia in the metabolic syndrome: importance of type 2 diabetes and familial combined involved in conceptualization of manuscript, obtained resources and mentoring of work. All authors contributed to the article and approved the submitted version.

\section{ACKNOWLEDGMENTS}

We acknowledge AYUSH for funding and Department of Biotechnology, India for DBT-RAship program.

\section{SUPPLEMENTARY MATERIAL}

The Supplementary Material for this article can be found online at: https://www.frontiersin.org/articles/10.3389/fendo.2020. 507064/full\#supplementary-material.

SUPPLEMENTARY TABLE 1 | Assessments phase.

SUPPLEMENTARY TABLE 2 | Diet information.

SUPPLEMENTARY TABLE 3 | Schedule of 5-day training camps of YogaCertified Volunteers for Diabetes Movement in different zones.

SUPPLEMENTARY TABLE 4 | for Physical activity measurement.

hyperlipidemia in coronary artery disease risk. J Clin Endocrinol Metab (2004) 89:2601-7.

14. Bauman AE, Reis RS, Sallis JF, Wells JC, Loos RJ, Martin BW, et al. Correlates of physical activity: why are some people physically active and others not? Lancet (2012) 380:258-71.

15. Zhao L, Zhang F, Ding X, Wu G, Lam YY, Wang X, et al. Gut bacteria selectively promoted by dietary fibers alleviate type 2 diabetes. Science (2018) 359:1151-6.

16. Galisteo M, Duarte J, Zarzuelo A. Effects of dietary fibers on disturbances clustered in the metabolic syndrome. J Nutr Biochem (2008) 19:71-84.

17. Brennan CS. Dietary fibre, glycaemic response, and diabetes. Mol Nutr Food Res (2005) 49:560-70.

18. Organization WH. Sugar Intake for Adults and Children: Guideline (2015). Available at: http://www.who.int/nutrition/publications/guidelines/sugars_ intake/en (Accessed May 10). 2016.

19. Misra A, Pandey R, Devi JR, Sharma R, Vikram N, Khanna N. High prevalence of diabetes, obesity and dyslipidaemia in urban slum population in northern India. Int J Obes (2001) 25:1722.

20. Nagarathna R, Rajesh S, Amit S, Patil S, Anand A, Nagendra H. Methodology of Niyantrita Madhumeha Bharata Abhiyaan-2017, a nationwide multicentric trial on the effect of a validated culturally acceptable lifestyle intervention for primary prevention of diabetes: Part 2. Int J Yoga (2019) 12:193.

21. Nagendra H, Nagarathna R, Rajesh S, Amit S, Telles S, Hankey A. Niyantrita Madhumeha Bharata 2017, methodology for a nationwide diabetes prevalence estimate: Part 1. Int J Yoga (2019) 12:179.

22. Weber MB, Ranjani H, Staimez LR, Anjana RM, Ali MK, Narayan KM, et al. The Stepwise Approach to Diabetes Prevention: Results From the D-CLIP Randomized Controlled Trial. Diabetes Care (2016) 39:1760-7.

23. Ramachandran A, Snehalatha C, Mary S, Mukesh B, Bhaskar AD, Vijay V. The Indian Diabetes Prevention Programme shows that lifestyle modification and metformin prevent type 2 diabetes in Asian Indian subjects with impaired glucose tolerance (IDPP-1). Diabetologia (2006) 49:289-97.

24. Ramachandran A, Snehalatha C, Kapur A, Vijay V, Mohan V, Das AK, et al. High prevalence of diabetes and impaired glucose tolerance in India: National Urban Diabetes Survey. Diabetologia (2001) 44:1094-101.

25. Mohan V, Deepa R, Deepa M, Somannavar S, Datta M. A simplified Indian Diabetes Risk Score for screening for undiagnosed diabetic subjects. J Assoc Physicians India (2005) 53:759-63. 
26. Adhikari P, Pathak R, Kotian S. Validation of the MDRF-Indian Diabetes Risk Score (IDRS) in another south Indian population through the Boloor Diabetes Study (BDS). J Assoc Physicians India (2010) 58:434-6.

27. Peters T, Brage S, Westgate K, Franks PW, Gradmark A, Tormo Diaz MJ, et al. Validity of a short questionnaire to assess physical activity in 10 European countries. Eur J Epidemiol (2012) 27:15-25.

28. Deshpande AD, Harris-Hayes M, Schootman M. Epidemiology of diabetes and diabetes-related complications. Phys Ther (2008) 88:1254-64.

29. U.P. Division. The impact of population momentum on future population growth. United Nations, Department of Economic and Social Affairs Population Division (2017). Available at: https://esa.un.org/unpd/wpp/ publications/Files/PopFacts_2017-4_Population-Momentum.pdf.

30. Zheng Y, Ley SH, Hu F.B.J.N.R.E. Global aetiology and epidemiology of type 2 diabetes mellitus and its complications. Nat Rev Endocrinol (2018) 14:88.

31. Mohan V. Why are Indians more prone to diabetes? J Assoc Physicians India (2004) 52:468-74.

32. Avijit B, Brown RE, Bamburg J, Khurana DKLD, Friedland RP, Chen W, et al. Translation of Pre-Clinical Studies into Successful Clinical Trials for Alzheimer's Disease: What are the Roadblocks and How Can They Be Overcome? Journal of Alzheimer's Disease. Scandinavian J Med Sci Sports (2015) 47(4):815-43.

33. Akshay A, Sharma NK, Gupta A, Prabhakar S, Sharma SK, Singh R, et al. Single nucleotide polymorphisms in MCP-1 and its receptor are associated with the risk of age related macular degeneration. PloS One (2012) 7(11): e49905.

34. Kaushal S, Sharma NK, Anand A. Why AMD is a disease of ageing and not of development: mechanisms and insights. Front Aging Neurosci (2014) 6:151.

35. Bali P, Banik A, Banik B, Nehru B, Anand A. Neurotrophic factors mediated activation of astrocytes ameliorate memory loss by amyloid clearance after transplantation of lineage negative stem cells. Mol Neurobiol (2019) 56 (12):8420-34.

36. Wong J, Constantino M, Yue D. Morbidity and mortality in young-onset type 2 diabetes in comparison to type 1 diabetes: where are we now? Curr Diab Rep (2015) $15: 566$.
37. Papazafiropoulou AK, Papanas N, Melidonis A, Maltezos E. Family history of type 2 diabetes: does having a diabetic parent increase the risk? Curr Diabeted Rev (2017) 13:19-25.

38. Sheard NF, Clark NG, Brand-Miller JC, Franz MJ, Pi-Sunyer FX, Mayer-Davis E, et al. Dietary carbohydrate (amount and type) in the prevention and management of diabetes: a statement by the American Diabetes Association. Diabetes Care (2004) 27:2266-71.

39. Tonstad S, Butler T, Yan R, Fraser G. Type of vegetarian diet, body weight and prevalence of type 2 diabetes. Diabetes Care (2009) 32(5):791-6.

40. Maiorino MI, Bellastella G, Giugliano D, Esposito Ki. complications. Can diet prevent diabetes? J Diabetes Complications (2017) 31:288-90.

41. Knowler WC, Barrett-Connor E, Fowler SE, Hamman RF, Lachin JM, Walker $\mathrm{EA}$, et al. Reduction in the incidence of type 2 diabetes with lifestyle intervention or metformin. N Engl J Med (2002) 346:393-403.

42. Fehm H, Kern W, Peters A. The selfish brain: competition for energy resources. Prog Brain Res (2006) 153:129-40.

43. Iborra R, Ribeiro I, Neves M, Charf A, Lottenberg S, Negrão C, et al. Aerobic exercise training improves the role of high-density lipoprotein antioxidant and reduces plasma lipid peroxidation in type 2 diabetes mellitus. Scandinavian J Med Sci Sports (2008) 18:742-50.

44. Huang TT, Goran MII. Prevention of type 2 diabetes in young people: a theoretical perspective. Pediatr Diabetes (2003) 4:38-56.

Conflict of Interest: The authors declare that the research was conducted in the absence of any commercial or financial relationships that could be construed as a potential conflict of interest.

Copyright (C) 2020 Nagarathna, Bali, Anand, Srivastava, Patil, Sharma, Manasa, Pannu, Singh and Nagendra. This is an open-access article distributed under the terms of the Creative Commons Attribution License (CC BY). The use, distribution or reproduction in other forums is permitted, provided the original author(s) and the copyright owner(s) are credited and that the original publication in this journal is cited, in accordance with accepted academic practice. No use, distribution or reproduction is permitted which does not comply with these terms. 